\title{
Androgen Receptor Antisense Oligonucleotide EZN-4176
}

National Cancer Institute

\section{Source}

National Cancer Institute. Androgen Receptor Antisense Oligonucleotide EZN-4176. NCI

Thesaurus. Code C96742.

A locked nucleic acid (LNA)-based antisense olig onucleotide targeting the androgen receptor (AR) mRNA, with potential antineoplastic activity. Upon administration, EZN4176 is hybridized and releases the complementary sequences of AR mRNA, thereby blocking translation of the AR protein and inhibiting AR-induced tumor cell growth and promoting tumor cell apoptosis in AR-overexpressing tumor cells. AR is overexpressed in certain breast and prostate cancers and is involved in tumor cell proliferation and survival. LNAs contain a methylene bridge linking 2'-oxygen and 4'-carbon of ribose sugar rings, thereby increasing their thermal stability and decreasing degradation. 